\title{
Review \\ Galleria mellonella: The Versatile Host for Drug Discovery, In Vivo Toxicity Testing and Characterising Host-Pathogen Interactions
}

\author{
Magdalena Piatek, Gerard Sheehan and Kevin Kavanagh *(D) \\ SSPC Pharma Research Centre, Department of Biology, Maynooth University, Maynooth, \\ W23 F2K8 Co. Kildare, Ireland; magdalena.piatek@mu.ie (M.P.); gerardsheehan1@gmail.com (G.S.) \\ * Correspondence: kevin.kavanagh@nuim.ie; Tel.: +353-1-708-3859
}

Citation: Piatek, M.; Sheehan, G.; Kavanagh, K. Galleria mellonella: The Versatile Host for Drug Discovery, In Vivo Toxicity Testing and Characterising Host-Pathogen Interactions. Antibiotics 2021, 10, 1545. https://doi.org/10.3390/ antibiotics 10121545

Received: 25 November 2021 Accepted: 14 December 2021 Published: 17 December 2021

Publisher's Note: MDPI stays neutral with regard to jurisdictional claims in published maps and institutional affiliations.

Copyright: (c) 2021 by the authors. Licensee MDPI, Basel, Switzerland. This article is an open access article distributed under the terms and conditions of the Creative Commons Attribution (CC BY) license (https:// creativecommons.org/licenses/by/ $4.0 /)$.

\begin{abstract}
Larvae of the greater wax moth, Galleria mellonella, are a convenient in vivo model for assessing the activity and toxicity of antimicrobial agents and for studying the immune response to pathogens and provide results similar to those from mammals. G. mellonella larvae are now widely used in academia and industry and their use can assist in the identification and evaluation of novel antimicrobial agents. Galleria larvae are inexpensive to purchase and house, easy to inoculate, generate results within $24-48 \mathrm{~h}$ and their use is not restricted by legal or ethical considerations. This review will highlight how Galleria larvae can be used to assess the efficacy of novel antimicrobial therapies (photodynamic therapy, phage therapy, metal-based drugs, triazole-amino acid hybrids) and for determining the in vivo toxicity of compounds (e.g., food preservatives, ionic liquids) and/or solvents (polysorbate 80). In addition, the disease development processes are associated with a variety of pathogens (e.g., Staphylococcus aureus, Listeria monocytogenes, Aspergillus fumigatus, Madurella mycotomatis) in mammals are also present in Galleria larvae thus providing a simple in vivo model for characterising disease progression. The use of Galleria larvae offers many advantages and can lead to an acceleration in the development of novel antimicrobials and may be a prerequisite to mammalian testing.
\end{abstract}

Keywords: antimicrobial; Galleria; in vivo testing; in vivo toxicity

\section{Introduction}

Insects possess a highly successful immune system that rapidly identifies pathogens and parasites and either kills them directly or immobilises them thus ensuring the survival of the host [1]. A wide range of structural and functional similarities exist between the insect immune response and the innate immune response of mammals [2,3] and, as a result, a wide variety of insects (Galleria mellonella, Drosophila melanogaster, Manduca sexta, Bombyx mori) is now used as in vivo models for assessing microbial virulence or for evaluating the in vivo efficacy and toxicity of antimicrobial compounds [4-7]. Larvae of the greater wax moth (Galleria mellonella) are widely used in academia and industry and in many cases generate results comparable to those that can be obtained using mammals [8-10]. Larvae have the advantage of being inexpensive to purchase and house, easy to manipulate, and being free from the legal and ethical restrictions that hinder vertebrate use [11]. This review will provide an insight into how Galleria larvae can be used to assess the in vivo efficacy and toxicity of novel antibacterial and antifungal agents and also to study disease development processes in vivo. As the number of applications of using Galleria larvae increase, their contribution to accelerating new drug development will increase.

\section{G. mellonella Larvae as a Vehicle for In Vivo Antibacterial Drug Assessment}

The multidrug resistant "ESKAPE" pathogens (Enterococcus faecium, Staphylococcus aureus, Klebsiella pneumoniae, Acinetobacter baumannii, Pseudomonas aeruginosa and Enterobacter spp.) are among a few that have rendered conventional antimicrobial therapies inactive, 
some of which are detailed below [12]. Due to increasing incidences of these resistant bacterial isolates to conventional antibiotics, there is an urgent need to develop novel antimicrobials with distinct modes of action. The use of Galleria larvae has contributed to this objective by allowing the accelerated in vivo assessment of potentially novel antimicrobial therapies. Phage therapy has proven effective against biofilm formation and aids penetration of antibiotics and/or cell lysis [13]. G. mellonella larvae have been used to assess a cocktail of phages CDHM 1, 2, 5 and 6 (multiplicity of infection =10), as individual treatments and synergistically with vancomycin $(64 \mu \mathrm{g} / \mathrm{g})$. Prophylactical treatment offered the greatest level of protection against Clostridium difficile infection with $100 \%$ larval survival after $60 \mathrm{~h}$. Further analysis indicated an increase in phage efficacy and reduction in bacterial load following prophylactic use of vancomycin [14].

Photodynamic therapy promoted the survival of G. mellonella larvae exposed to the periodontal pathogen Porphyromonas gingivalis. Inoculation of $1 \times 10^{6}$ colony forming units (CFUs) of $P$. gingivalis per larva followed by $120 \mathrm{~s}$ of photodynamic therapy maintained $75 \%$ larval survival compared to untreated samples. This therapy also induced an immune response and a 2.62-fold increase in haemocyte (immune cell) density. Disruption of bacterial membranes enabling more efficient haemocyte-mediated phagocytosis was the suspected mode of action of this therapy [15].

Four novel manganese-based compounds have been assessed for their antibacterial activity through the weakening of bacterial membrane integrity: $\left[\mathrm{Mn}\left(\right.\right.$ bpqa- $\left.\left.{ }^{3} N\right)(\mathrm{CO})_{3}\right] \mathrm{Br}$, $\left[\mathrm{Mn}\left(\mathrm{bqpa}-\kappa^{3} N\right)(\mathrm{CO})_{3}\right] \mathrm{Br},\left[\mathrm{Mn}(\mathrm{CO})_{3}\left(\mathrm{tqa}-\kappa^{3} N\right)\right] \mathrm{Br}$ and $\left[\mathrm{Mn}(\mathrm{CO})_{3}\left(\mathrm{tpa}-\kappa^{3} N\right) \mathrm{Br}\right.$. Larvae infected with two multidrug-resistant clinical isolates of Acinetobacter baumannii and Pseudomonas aeruginosa were administered $5 \mathrm{mg} / \mathrm{kg}$ of $\left[\mathrm{Mn}(\mathrm{CO})_{3}\left(\operatorname{tqa}-\mathrm{k}^{3} \mathrm{~N}\right)\right] \mathrm{Br}$ (Figure 1) and observed at 24-h intervals. Approximately $80 \%$ of $A$. baumannii-infected larvae treated with the compound survived after $96 \mathrm{~h}$ in comparison with $50 \%$ of $P$. aeruginosa infected larvae [16].<smiles></smiles>

Figure 1. Chemical structure of $\left[\mathrm{Mn}(\mathrm{CO})_{3}\left(\operatorname{tqa}-\kappa^{3} N\right)\right] \mathrm{Br}$ evaluated in vivo. Adapted image [16].

Silver is a well-established component of many antimicrobial therapies used in wound dressings, creams and medical device coatings in healthcare settings [17]. G. mellonella larvae were employed to assess the effective dosing concentrations of silver nanoparticles (AgNPs). Toxicity evaluation deemed concentrations below $35 \mathrm{mg} / \mathrm{kg}$ suitable for in vivo use. Prophylactic treatment $(25 \mathrm{mg} / \mathrm{kg}$ ) resulted in $80 \%$ larval survival for up to four days while larvae infected with a highly virulent clinical isolate of $P$. aeruginosa developed disease symptoms and/or died in the first $24 \mathrm{~h}$. Prophylactic treatment enhanced haemocyte production and maintained phenoloxidase activity similar to uninfected larvae. Lower levels of phenoloxidase and the presence of haemocyte nodules (which entrap and kill invading microbes) in response to AgNPs explained the reduced levels of melanisation of treated larvae $[18,19]$.

G. mellonella larvae were administered the antimicrobial peptide-containing hydrogel (Naphthalene-2-ly)-acetyl-diphenylalanine-dilysine-OH (NapFFKK-OH) (Figure 2) via intra-hemocoel injection. Larvae injected with $0.5-2 \%(w / v)$ NapFFKK-OH maintained full survival up to $120 \mathrm{~h}$, demonstrating more desirable results compared to in vitro assessment on murine fibroblast cells. In vivo testing revealed improved tolerability and the capacity to reduce bacterial loads after 24 and $72 \mathrm{~h}$. The presence of viable Staphylococcus epidermidis, Staphylococcus 
aureus, Escherichia coli and P. aeruginosa decreased in a dose dependent manner, particularly in the case of $S$. aureus $72 \mathrm{~h}$ post-treatment $\left(4.4 \log _{10} \mathrm{CFU} / \mathrm{mL}\right.$ reduction) [20].<smiles>NCCCCC(NC(=O)C(CCCCN)NC(=O)C(Cc1ccccc1)NC(=O)C(Cc1ccccc1)NC(=O)Cc1ccc2ccccc2c1)C(=O)O</smiles>

Figure 2. NapFFKK-OH hydrogel chemical structure. Adapted image [20].

\section{Application of G. mellonella Larvae in Antifungal Drug Evaluation}

Novel metal based antifungal therapies have been evaluated in Galleria larvae and results have shown potential applications in mammals. Rowan et al., (2009) assessed the antifungal efficacy of $\left(\left[\mathrm{Ag}_{2}(\mathrm{mal})(\mathrm{phen})_{3}\right], \mathrm{AgNO}_{3}\right.$ and 1,10-phenanthroline for their activity against Candida albicans in G. mellonella larvae. Larvae infected with $5 \times 10^{5} \mathrm{C}$. albicans cells were treated prior to and post infection. Treatment one hour after infection ensured approximately $80 \%$ survival in all treatments after $24 \mathrm{~h}$. This decreased to approximately $65 \%$ after $48 \mathrm{~h}$ and $30-40 \%$ after $72 \mathrm{~h}$ across all treatment types [21]. An alternative silver-based compound, 1,3-dibenzyl-4,5-diphenyl-imidazol-2-ylidene silver(I) acetate (SBC3) (Figure 3) has displayed potent antifungal activity, specifically against C. albicans. In vitro exposure to $25 \mu \mathrm{g} / \mathrm{mL} \mathrm{SBC3}$ inhibited C. albicans growth by $86.2 \pm 1.42 \%$. To verify this activity in vivo, larvae were firstly subjected to a lethal inoculum of $C$. albicans $\left(1 \times 10^{6}\right.$ cells $)$ that induced $100 \%$ mortality after $48 \mathrm{~h}$. Treatment with $20 \mu \mathrm{L}$ doses of 10, 100 and $250 \mu \mathrm{L} / \mathrm{mL}$ SBC3 four hours post-infection lead to $30 \pm 5.77,16.7 \pm 6.66$ and $13.3 \pm 3.33 \%$ survival of larvae, respectively, after $72 \mathrm{~h}$. Importantly, SBC3 alone did not elicit an immune response or toxic reaction in larvae [22].<smiles>CC(=O)ON1C(c2ccccc2)=C(c2ccccc2)N(Cc2ccccc2)C1Cc1ccccc1</smiles>

Figure 3. Chemical structure of SBC3.

Copper(II), Manganese(II), and Silver(I) 1,10-phenanthroline chelates displayed potent antifungal activity against Candida haemulonii. Eleven complexes containing copper, manganese and/or phen were administered one hour post-infection with $5 \times 10^{5} \mathrm{C}$. haemulonii cells at concentrations of 5, 2.5, 1.25 and $0.625 \mu \mathrm{g} /$ larva. Manganese-phen complexes appeared the most potent in reducing fungal load after 24 and $48 \mathrm{~h}$. Prophylactic treatment $24 \mathrm{~h}$ in advance provided high levels of protection and reduced mortality by $55-100 \%$ after $24 \mathrm{~h}$ of infection. The previous evaluation identified non-toxic doses and increases in haemocyte density in response to some of the chelates [23].

Lim et al., (2018) identified ten compounds out of 800 with potent activity against Madurella mycetomatis in G. mellonella larvae. The top ten most active compounds that significantly enhanced larval survival include MMV-006357, -675968 and -022478. Out of five assessed fenarimol analogues, EPL-BS0178, -BS0495 and -BS1205 promoted survival 
by $36.7 \%, 24.1 \%$ and $19.2 \%$, respectively. It has been suggested that the success of these fenarimols is attributed to their high polarity, and therefore, greater permeability and tissue delivery [24].

Triazole-amino acid hybrids have shown strong promise as novel anticandidal treatments. These compounds, which bear an indole moiety, inhibit ergosterol biosynthesis and damage cell wall integrity. They are particularly effective in combination with current azoles [25,26]. A series of 24 compounds were screened to identify 1,2,3-triazoles consisting of phenylalanine and tryptophan tails as the most potent against fluconazole-resistant C. albicans. Compounds 68 and 70 (Figure 4) were non-toxic up $2.5 \mathrm{mg} / \mathrm{mL}$ in G. mellonella larvae and at this concentration could reduce $C$. albicans growth by approximately 50 and $70 \%$, respectively. The compounds did not elicit an immune response as haemocyte density counts were unaltered [26].<smiles>NC(Cc1ccccc1)C(=O)OCc1cn(CCC(=O)NCc2ccc(F)cc2)nn1</smiles><smiles>NC(Cc1c[nH]c2ccccc12)C(=O)OCc1cn(CCC(=O)NCc2ccc(F)cc2)nn1</smiles>

Figure 4. Chemical structure of Compounds 68 and 70. Adapted images [26].

Pedalitin (Figure 5), a flavonoid extracted from Pterogyne nitens tree leaves, was injected alone and in combination with amphotericin B into G. mellonella larvae. No larvae survived after four days following infection with $1 \times 10^{6}$ cells $C$. neoformans whereas combination therapy (amphotericin B, $0.3 \mathrm{mg} / \mathrm{kg}$ and pedalitin, $10 \mathrm{mg} / \mathrm{kg}$ ) rescued approximately $80 \%$ and $60 \%$ of larvae at this time point and after seven days, respectively. Histopathology of larvae over three days supported these findings- untreated larvae experienced severe tissue damage in response to the yeast $\left(1 \times 10^{6}\right.$ cells $\left./ \mathrm{mL}\right)$ in contrast with individual (amphotericin B, $4 \mathrm{mg} / \mathrm{kg}$; pedalitin $40 \mathrm{mg} / \mathrm{kg}$ ) and combination therapy (amphotericin B, $0.3 \mathrm{mg} / \mathrm{kg}$; pedalitin $10 \mathrm{mg} / \mathrm{kg}$ ). The efficacy of pedalitin and/or amphotericin B in G. mellonella was comparable with murine results where combination therapy promoted $40 \%$ survival after 40 days. Infections are typically managed with fluconazole and amphotericin B however, pedalitin has shown potential as a less toxic alternative for cryptococcosis [27].<smiles>COc1cc2oc(-c3ccc(O)c(O)c3)cc(=O)c2c(O)c1O</smiles>

Figure 5. Chemical structure of pedalitin. Adapted image [28]. 


\section{G. mellonella Larvae as a Novel In Vivo System for Toxicity Studies}

Galleria larvae provide a fast and convenient means to assess in vivo toxicity and results show a strong correlation to those from mammalian systems. The Global Harmonising System of Classification and Labelling of Chemicals (GHS) classifies the acute toxicity of hazardous chemicals into five categories ranging from low toxicity (category 5) to high toxicity (category 1 ) and are based on the median lethal dose $\left(\mathrm{LD}_{50}\right)$ (oral, dermal) and $\mathrm{IC}_{50}$ (inhalation) values [29]. A strong correlation between GHS classification and the G. mellonella larval response to several chemicals in comparison with 3T3 and NKH cell lines and in a murine model has been demonstrated [30]. The survival rates of larvae and $\mathrm{LD}_{50}$ values were determined following treatment with 19 soluble chemicals including disulfoton, cadmium chloride, phenol, citric acid, sodium hypochlorite and glycerol. The larval response to nine of these chemicals that were assigned to GHS category 5 correlated strongly with GHS classified measurements whereas only four out of nine tested on 3T3 and NHK cell lines matched GHS classification. Cell culture assays can exaggerate the toxicity of chemicals and so for this reason, in vivo analysis using G. mellonella larvae may provide a more accurate representation of low toxicity chemicals prior to animal testing [30].

A system of controlled chemical dosage based on the larval response after five days was devised [31]. G. mellonella larvae were initially administered $5 \mathrm{mg} / \mathrm{kg}$ and if $\geq 60 \%$ larvae survived after five days, new larvae were subjected to higher doses in a sequential manner up to a maximum dose of $2000 \mathrm{mg} / \mathrm{kg}$ to establish a toxic dose. Chemicals that induced $40 \%$ mortality following the starting dose were classified as GHS category 1 whilst those given $2000 \mathrm{mg} / \mathrm{kg}$ concentrations that resulted in 100\% survival were deemed nontoxic. Calculated $\mathrm{LD}_{50}$ values for all 11 compounds were compared to known values according to the corresponding Material Safety Data Sheet (MSDS). Compounds such as doxorubicin showed the lowest $\mathrm{LD}_{50}$ value and proved most toxic to larvae matched values corresponding with mammalian models $(5.5 \mathrm{mg} / \mathrm{kg}$ for G. mellonella versus 1.2 and $16 \mathrm{mg} / \mathrm{kg}$ in mice and rats, respectively). It is evident that G. mellonella larvae are strong candidates for acute toxicity testing and can help predict the toxic response in higher organisms thereby reducing the quantity of vertebrates required [31].

The toxicity of widely used food preservatives was examined to validate the suitability of G. mellonella as a toxicity screening model. Larvae were administered with potassium nitrate, potassium nitrite, potassium sorbate, sodium acetate, sodium benzoate, sodium chloride, sodium nitrate and sodium nitrite via force-feeding or intra-hemocoel injection and monitored over $48 \mathrm{~h}$. All preservatives proved toxic to the host however, increased bioavailability post intra-hemocoel administration generated lower $\mathrm{LD}_{50}$ values in comparison with force-fed samples. Force feeding and intra-hemocoel injection $\mathrm{LD}_{50}$ values demonstrated a positive correlation with $\mathrm{IC}_{50}$ values calculated from human epithelial type 2 (HEp-2) cells after exposure to these preservatives. In addition, the relative toxicity corresponded with previously recorded results from murine models [32].

Ionic liquids are considered toxic, particularly those that consist of longer alkyl and hydroxyl chains. Imidazole-based ionic liquids are widely used in industry, however, they have demonstrated various levels of toxicity to enzymes, mammalian cells, and model organisms with regards to growth, viability and/or reproduction rates [33-36]. The survival of G. mellonella larvae was observed to estimate $\mathrm{LD}_{50}$ values of nine 1-alkyl-3methylimidazolium chlorides with varied alkyl chains ranging from two to 18 carbon atoms. Chain lengths of $C_{8}$ accounted for the highest level of toxicity with an $\mathrm{LD}_{50}$ of $11.7 \mu \mathrm{g} / \mathrm{g}$. Thereafter, toxicity decreased with $\mathrm{LD}_{50} 69.2 \mu \mathrm{g} / \mathrm{g}$ for chain lengths of $\mathrm{C}_{18}$. The correlation between increased chain length and toxicity coincides with previous studies on other model organisms to a certain extent however, the high fat content in larvae and increasing lipophilicity of the compounds likely causes compound aggregation and reduced bioavailability in host tissues [37].

There is limited knowledge regarding optimal testing conditions in G. mellonella however, PBS, water, and DMSO $(<20 \%)$ are the most widely used solvents for compound testing. Suay-García et al., (2019) analysed the tolerability of five aqueous solvents (acetic 
acid, $\mathrm{DMSO}, \mathrm{HCl}, \mathrm{MeOH}$ and $\mathrm{NaOH}$ ) and four non-aqueous solvents (benzyl benzoate, ethyl oleate, isopropyl myristate and olive oil) in G. mellonella. All nine solvents were regarded as non-toxic and suitable for use in larvae except $\mathrm{NaOH}$ where concentrations above $0.5 \mathrm{M}$ were lethal to $50 \%$ of larvae. The maximum concentrations of DMSO, $\mathrm{MeOH}$ and acetic acid were kept at $30 \%$. Higher concentrations possess antimicrobial activity, and therefore, misrepresent drug activity in antimicrobial testing. Moreover, amino salicylic acid was selected as a compound to validate the delivery potential of these solvents. $\mathrm{NaOH}(0.5 \mathrm{M})$ successfully dissolved 50,125 and $300 \mathrm{mg} / \mathrm{kg}$ doses of amino salicylic acid for larval administration whereas previous studies have eliminated its use due to solubility issues [38].

The safety of nanomaterial drug delivery systems must also be considered. For example, the size of nanoparticles and charge contribute to different levels of reactivity. Neutral and negative charges tend to be less reactive and hence less toxic in comparison to positively charged nanoparticles. G. mellonella larvae have been employed to assess the toxicity of lipid-core nanocapsules composed of polysorbate 80 (LNC-1), lecithin and polysorbate 80 (LNC-2) and lecithin, chitosan and polysorbate 80 (LCN-3). These lipid-core nanocapsules coated with micellar layers and a lipophilic crown provide a protective coating for drugs to prolong blood circulation and enhance delivery to specific targets. This study challenged larvae with formulations of LNC-1, 2 and 3 at concentrations ranging from $3.75 \times 10^{-14}$ to $3.75 \times 10^{-10} \mathrm{~mol} / \mathrm{kg}$ via intra-hemocoel injection and monitored survival for $120 \mathrm{~h}$. Survival rates were similar to those of DMSO and water control samples and showed no distinction between neutral, negative and positive nanocapsules. Moreover, Wistar rats treated with LNC-1,2 and 3 over 28 days demonstrated no signs of cardio-, nephro- or hepatotoxicity. There was also no evidence of tissue damage following blood and urine analyses or obvious signs of oxidative stress [39]. Thus, G. mellonella larvae were suggested as strong candidates for toxicity studies of nanomaterials [40].

\section{Application of G. mellonella Larvae to Characterise Microbial Disease Development Processes In Vivo}

Galleria larvae are susceptible to infection by a wide range of bacterial and fungal pathogens. Recent work has highlighted how many of the pathologies associated with human infection by these pathogens are also visible in larvae as the infections develop. Infection of G. mellonella larvae with Staphylococcus aureus resulted in a dose dependent decrease in larval viability at $37^{\circ} \mathrm{C}$ [41] (Figure 6). In mice, an inoculum of $10^{8} \mathrm{CFU} /$ mouse resulted in 50\% survival after 2 days and $0 \%$ survival after four days [42]. In neutrophil depleted mice, S. aureus can proliferate significantly within blood and skin samples [43]. By $48 \mathrm{~h}$, widespread melanisation of insect haemolymph occurred possibly due to uncontrolled phenoloxidase activation as a result of bacterial replication [41]. Nodules produced in G. mellonella larvae during infection were similar in structure and composition to abscesses commonly found during S. aureus skin and soft tissue infection in humans [44]. S. aureus produces several molecules that contribute to abscess formation which recruit neutrophils, induce host cell lysis and the formation of the fibrin capsule surrounding the abscess [44]. Within $72 \mathrm{~h}$ staphylococci are localised within abscess at the centre of the lesions, enclosed by fibrin deposits, and surrounded by layers of immune cells $[45,46]$.

Listeria monocytogenes displayed significant pathogenesis in G. mellonella larvae, and this was attributed to the expression of a range of virulence factors. Hexose phosphate transporter (uhpT), was essential for virulence, but factors such as PlcA appeared to be dispensable for virulence which was previously established in human umbilical vein endothelial cell (HUVEC) monolayers [47,48]. There was a large reduction in L. monocytogenes CFUs in larvae one hour post-infection suggesting the presence of effective constitutively expressed components of innate immune responses [47]. A range of AMPs such as gallerimycin, and lysozyme, were induced at six hours post-infection as assessed by qPCR and it was shown that inoculation of larvae with increasing concentrations of LPS augmented survival of larvae and the antimicrobial activity of haemolymph [47]. 


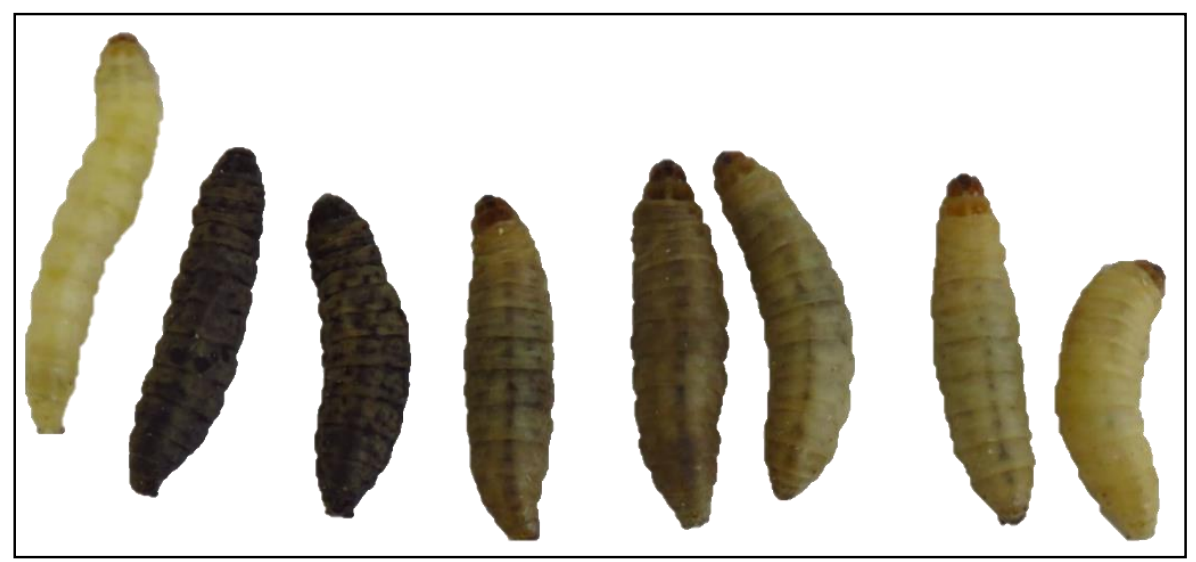

Figure 6. G. mellonella larvae with varying degrees of $S$. aureus infection $24 \mathrm{~h}$ post-inoculation. Larvae were injected with $20 \mu \mathrm{L}$ of cell suspension in PBS and incubated at $37^{\circ} \mathrm{C}$ for $24 \mathrm{~h}$. S. aureus cell inoculum/larva from left to right: uninfected control larva (PBS only), $2 \times 10^{8}, 1 \times 10^{8}, 5 \times 10^{7}$, $2 \times 10^{7}, 1.5 \times 10^{7}, 1 \times 10^{7}, 5 \times 10^{6}$ cells/larva.

L. monocytogenes can induce the expression of gloverin and moricin AMPs during infection, target the central nervous system of G. mellonella larvae and relies on the same virulence factors required for human infection during infection of larvae [49]. Infection was associated with the formation of melanised nodules throughout the host as well as in the brains of larvae. Furthermore, Listeria infection resulted in developmental shifts and changes in gene expression encoding growth hormones [49]. Inhibitors of autophagy (rapamycin) or host cyclo-oxygenase (diclofenac) enhanced survival in larvae but also have anti-listerial activity in mammals [49-51]. L. monocytogenes can penetrate the blood-brain barrier in larvae and induce a brain specific immune response and infection which results in significant alterations in insect development [49].

Klebsiella pneumoniae infection of G. mellonella larvae showed similar features to Klebsiella-induced pneumonia in mammals. Infection of mice with K. pneumoniae is primarily characterised by cellular necrosis due to a high bacterial burden which results in a profound inflammatory response [52]. In Galleria, Klebsiella resulted in larval death due to rapid proliferation in haemolymph and a large and early ( $12 \mathrm{~h}$ post-infection) increase in phenoloxidase activity [52]. Interestingly, as with murine macrophages, K. pneumoniae avoided phagocytosis by G. mellonella haemocytes [53]. K. pneumoniae also produced a robust antimicrobial response by the increased expression of lysozyme, galiomycin, cecropin, gallerimycin and IMPI, key components of the insect immune response [52].

G. mellonella larvae can be used to study Aspergillus fumigatus infection by comparing it to infection which occurs within the immunocompromised lung, or in those conditions which favour invasive aspergillosis [54]. A hallmark of invasive aspergillosis in the chronic granulomatous disease mouse model is the early germination of conidia and the formation of hyphae after $24 \mathrm{~h}$ with neutrophil infiltration and pyogranulomatous lesions surrounded by granulocytes [55]. During larval infection, there was dissemination of fungal material from the site of inoculation to distal sites and the resulting nodules consisted of granulocyte infiltration and encapsulation of A. fumigatus germinating conidia (Figure 7) [54]. Nodules showed similarities to granulomatous structures which are characteristic of invasive aspergillosis in the CGD murine model. The humoral immune response to A. fumigatus was examined and was associated with AMP production (gloverin, moricin, lysozyme, cecropin) and mediators of the phenoloxidase cascade (serpin-4B, prophenoloxidase activating enzyme 3 and prophenoloxidase activating factor 3) [54]. During the mammalian innate response to A. fumigatus, a range of antimicrobial peptides (defensins, cathelicidins) and proteins (lactoferrin, lysozyme) are produced and these are essential in curtailing early fungal establishment and growth [56,57]. Furthermore, the prophenoloxidase cascade is analogous to the mammalian complement protein cascade in terms of protein structure, 
function and mode of action $[58,59]$. During the later time point ( $24 \mathrm{~h}$ post-infection) proteins associated with tissue invasion (muscle protein 20 like protein), recognition and opsonization of fungal cells (hemolin, peptidoglycan recognition like protein B) and inhibition of fungal proteinases (insect metalloproteinase inhibitor (IMPI)) were increased in abundance $[54,60,61]$. A fumigatus produces a variety of metalloproteinases most notably Asp f5/mep, a $42 \mathrm{kDa} \mathrm{Zn} / \mathrm{Mep}$, which possesses collagenlytic and elastinolytic activity and are important for immune cell recruitment in the murine lung [62,63].

(a)

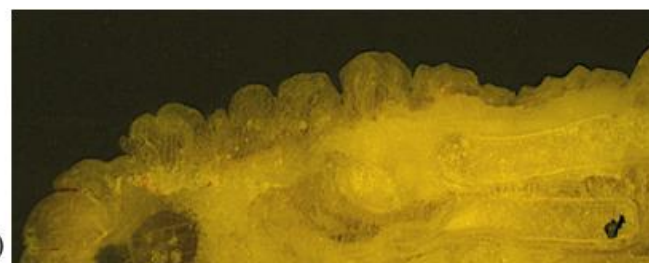

(b)

(c)

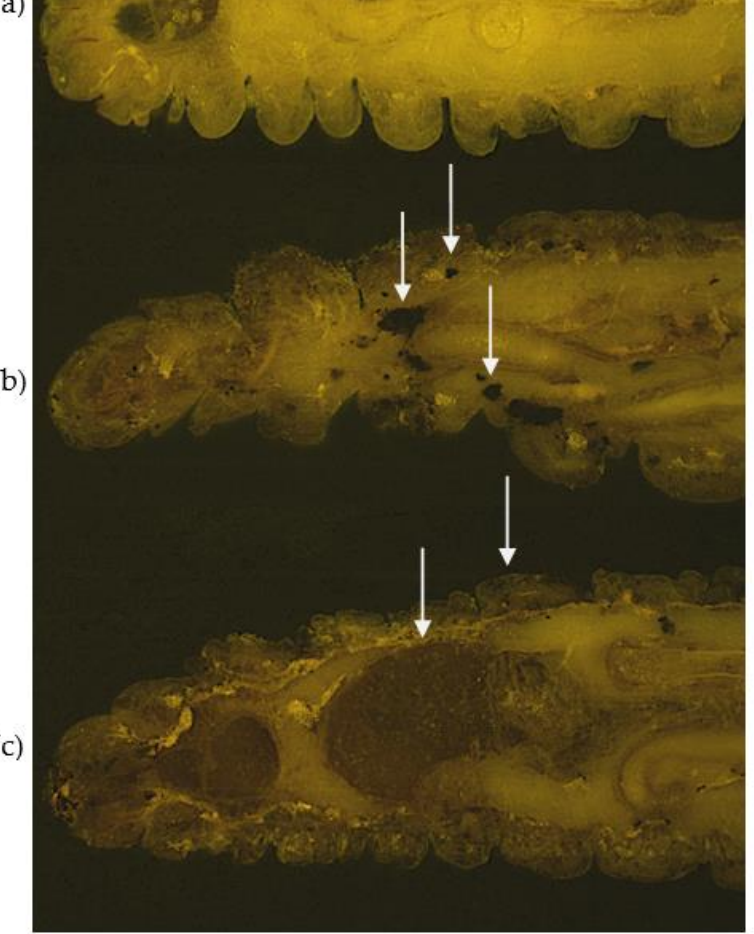

Figure 7. Cryo-images of A. fumigatus dissemination in the anterior sections of G. mellonella larvae after 24 h. (a) Uninfected larvae; larvae infected with $A$. fumigatus (b) $1 \times 10^{6}$ and (c) $1 \times 10^{7}$ viable conidia. Larvae were embedded in Cryo-imaging embedding compound and sectioned (10 $\mu \mathrm{m})$ using Cryoviz $^{\mathrm{TM}}$ (Bioinvision Inc., Cleveland, OH, USA). White arrows depict fungal nodules/granulomas (b), melanised tissue and organs and cuticle melanisation (c).

Madurella mycetomatis is the dominant causative agent of eumycetoma, a chronic granulomatous type infection that is severely debilitating to its sufferers due to its occurrence at the extremities of the body. A key feature of mycetoma is the presence of grains inside the tissue and these grains may be formed as a defence mechanism by the fungus against the host immune system [64]. Grains consist of lipids, protein and melanin and the melanin is located on hyphal walls as thick layers. Furthermore, zinc, copper and calcium concentrations are significantly higher in M. mycetomatis-infected samples than controls which contribute to the formation of the grain cement matrix [65]. A proteomic approach was employed to characterise $M$. mycetomatis grain formation in G. mellonella larvae and map the processes leading to grain formation over time [66]. In the first stage the G. mellonella immune system deployed a range of cellular and humoral measures to contain and prevent the growth of $M$. mycetomatis consisting of proteins able to recognize fungal pathogen-associated molecular pattern (PAMPs) ( $\beta$-glucan (PG-RPs) [67] and the opsonin 
lipopolysaccharide binding protein) [66]. M. mycetomatis responds by the production of vesicles associated proteins (e.g., GAPDH, enolase and fructose biosphosphate aldolase are known to bind constituents of the extracellular matrix) which were hypothesised to play a role in cement formation via transport of material into the extracellular space [66]. Furthermore, in the serum of eumycetoma patients, antibodies against M. mycetomatis fructose-bisphosphate aldolase and pyruvate kinase have been detected [68]. Immunohistochemistry demonstrated that fructose biosphosphate aldolase was expressed in the mammalian fungal grain [68].

\section{Conclusions}

G. mellonella is a highly versatile model organism that enables rapid in vivo assessment of the activity of antimicrobial compounds, the evaluation of the acute toxicity of a broad range of substances and the study of disease development processes which show strong similarities to infection processes in mammals. G. mellonella larvae are easy to inoculate and results are generated within $24-48 \mathrm{~h}$. They also have the advantage of having a wide range of endpoints for each assay that gives additional information to inform subsequent in vivo mammalian testing. Despite these many advantages, $G$. mellonella larvae require further development as a model organism. For example, the generation of mutant strains has not yet become a possibility thus preventing genomic studies [69]. Although immune priming offers some degree of protection against re-infection in Galleria larvae, the lack of adaptive immunity in the form of antibodies, cytokines, dendritic cells and natural killer cells makes it difficult to ascertain the mammalian immune response [70,71]. Lastly, discrepancies among experimental procedures and larval stock supplies warrant a more standardised approach [69]. While there are some limitations, interest in the use of G. mellonella larvae is increasing as they provide a rapid, easy to use in vivo system which can expedite antimicrobial drug development.

Author Contributions: M.P., G.S. and K.K. contributed equally to this manuscript. All authors have read and agreed to the published version of the manuscript.

Funding: M.P. is funded by a grant from Science Foundation Ireland (SFI) and is co-funded under the European Regional Development Fund under grant number 12/RC/2275_P2.

Acknowledgments: The production of this publication was supported by funding from a research grant from Science Foundation Ireland (SFI) and is co-funded under the European Regional Development Fund under grant number 12/RC/2275_P2.

Conflicts of Interest: The authors declare no conflict of interest.

\section{References}

1. Dhinaut, J.; Balourdet, A.; Teixeira, M.; Chogne, M.; Moret, Y. A dietary carotenoid reduces immunopathology and enhances longevity through an immune depressive effect in an insect model. Sci. Rep. 2017, 7, 12429. [CrossRef]

2. Browne, N.; Heelan, M.; Kavanagh, K. An analysis of the structural and functional similarities of insect hemocytes and mammalian phagocytes. Virulence 2013, 4, 597-603. [CrossRef] [PubMed]

3. Kavanagh, K.; Reeves, E.P. Exploiting the potential of insects for in vivo pathogenicity testing of microbial pathogens. FEMS Microbiol. Rev. 2004, 28, 101-112. [CrossRef] [PubMed]

4. Ong, C.; Yung, L.-Y.L.; Cai, Y.; Bay, B.-H.; Baeg, G.-H. Drosophila melanogaster as a model organism to study nanotoxicity. Nanotoxicology 2015, 9, 396-403. [CrossRef] [PubMed]

5. Lyons, N.; Softley, I.; Balfour, A.; Williamson, C.; O’Brien, H.E.; Shetty, A.C.; Bruno, V.M.; Diezmann, S. Tobacco hornworm (Manduca sexta) caterpillars as a novel host model for the study of fungal virulence and drug efficacy. Virulence 2020, 11, 1075-1089. [CrossRef] [PubMed]

6. Montali, A.; Berini, F.; Brivio, M.F.; Mastore, M.; Saviane, A.; Cappellozza, S.; Marinelli, F.; Tettamanti, G. A silkworm infection model for in vivo study of glycopeptide antibiotics. Antibiotics 2020, 9, 300. [CrossRef] [PubMed]

7. Desbois, A.P.; Coote, P.J. Wax moth larva (Galleria mellonella): An in vivo model for assessing the efficacy of antistaphylococcal agents. J. Antimicrob. Chemother. 2011, 66, 1785-1790. [CrossRef] [PubMed]

8. Miyata, S.; Casey, M.; Frank, D.W.; Ausubel, F.M.; Drenkard, E. Use of the Galleria mellonella caterpillar as a model host to study the role of the type III secretion system in Pseudomonas aeruginosa pathogenesis. Infect. Immun. 2003, 71, 2404-2413. [CrossRef]

9. Brennan, M.; Thomas, D.Y.; Whiteway, M.; Kavanagh, K. Correlation between virulence of Candida albicans mutants in mice and Galleria mellonella larvae. FEMS Immunol. Med. Microbiol. 2002, 34, 153-157. [CrossRef] 
10. Slater, J.L.; Gregson, L.; Denning, D.W.; Warn, P.A. Pathogenicity of Aspergillus fumigatus mutants assessed in Galleria mellonella matches that in mice. Med. Mycol. 2011, 49, S107-S113. [CrossRef]

11. Kavanagh, K.; Sheehan, G. The use of Galleria mellonella larvae to identify novel antimicrobial agents against fungal species of medical interest. J. Fungi 2018, 4, 113. [CrossRef] [PubMed]

12. Mulani, M.S.; Kamble, E.E.; Kumkar, S.N.; Tawre, M.S.; Pardesi, K.R. Emerging strategies to combat ESKAPE pathogens in the era of antimicrobial resistance: A review. Front. Microbiol. 2019, 10, 539. [CrossRef] [PubMed]

13. Hargreaves, K.R.; Clokie, M.R.J. Clostridium difficile phages: Still difficult? Front. Microbiol. 2014, 5, 184. [CrossRef]

14. Nale, J.Y.; Chutia, M.; Carr, P.; Hickenbotham, P.T.; Clokie, M.R.J. "Get in early"; Biofilm and wax moth (Galleria mellonella) models reveal new insights into the therapeutic potential of Clostridium difficile bacteriophages. Front. Microbiol. 2016, 7, 1383. [CrossRef]

15. dos Santos, J.D.; de Alvarenga, J.A.; Rossoni, R.D.; García, M.T.; Moraes, R.M.; Anbinder, A.L.; Cardoso Jorge, A.O.; Junqueira, J.C. Immunomodulatory effect of photodynamic therapy in Galleria mellonella infected with Porphyromonas gingivalis. Microb. Pathog. 2017, 110, 507-511. [CrossRef] [PubMed]

16. Güntzel, P.; Nagel, C.; Weigelt, J.; Betts, J.W.; Pattrick, C.A.; Southam, H.M.; La Ragione, R.M.; Poole, R.K.; Schatzschneider, U. Biological activity of manganese(i) tricarbonyl complexes on multidrug-resistant Gram-negative bacteria: From functional studies to in vivo activity in Galleria mellonella. Metallomics 2019, 11, 2033-2042. [CrossRef]

17. Wright, J.B.; Lam, K.; Hansen, D.; Burrell, R.E. Efficacy of topical silver against fungal burn wound pathogens. Am. J. Infect. Control 1999, 27, 344-350. [CrossRef]

18. Thomaz, L.; Gustavo de Almeida, L.; Silva, F.R.O.; Cortez, M.; Taborda, C.P.; Spira, B. In vivo activity of silver nanoparticles against Pseudomonas aeruginosa infection in Galleria mellonella. Front. Microbiol. 2020, 11, 2798. [CrossRef]

19. Trevijano-Contador, N.; Zaragoza, O. Immune response of Galleria mellonella against human fungal pathogens. J. Fungi 2018, 5, 3. [CrossRef]

20. McCloskey, A.P.; Lee, M.; Megaw, J.; McEvoy, J.; Coulter, S.M.; Pentlavalli, S.; Laverty, G. Investigating the in vivo antimicrobial activity of a self-assembling peptide hydrogel using a Galleria mellonella infection model. ACS Omega 2019, 4, 2584-2589. [CrossRef]

21. Rowan, R.; Moran, C.; McCann, M.; Kavanagh, K. Use of Galleria mellonella larvae to evaluate the in vivo anti-fungal activity of $\left[\mathrm{Ag}_{2}(\mathrm{mal})(\text { phen })_{3}\right]$. BioMetals 2009, 22, 461-467. [CrossRef]

22. Browne, N.; Hackenberg, F.; Streciwilk, W.; Tacke, M.; Kavanagh, K. Assessment of in vivo antimicrobial activity of the carbene silver(I) acetate derivative SBC3 using Galleria mellonella larvae. BioMetals 2014, 27, 745-752. [CrossRef]

23. Gandra, R.M.; McCarron, P.; Viganor, L.; Fernandes, M.F.; Kavanagh, K.; McCann, M.; Branquinha, M.H.; Santos, A.L.S.; Howe, O.; Devereux, M. In vivo activity of copper(II), manganese(II), and silver(I) 1,10-phenanthroline chelates against Candida haemulonii using the Galleria mellonella model. Front. Microbiol. 2020, 11, 470. [CrossRef] [PubMed]

24. Lim, W.; Melse, Y.; Konings, M.; Phat Duong, H.; Eadie, K.; Laleu, B.; Perry, B.; Todd, M.H.; Ioset, J.R.; van de Sande, W.W.J. Addressing the most neglected diseases through an open research model: The discovery of fenarimols as novel drug candidates for eumycetoma. PLoS Negl. Trop. Dis. 2018, 12, e0006437. [CrossRef] [PubMed]

25. Pawar, K.; Yadav, A.; Prasher, P.; Mishra, S.; Singh, B.; Singh, P.; Komath, S.S. Identification of an indole-triazole-amino acid conjugate as a highly effective antifungal agent. Medchemcomm 2015, 6, 1352-1359. [CrossRef]

26. Aneja, B.; Irfan, M.; Kapil, C.; Jairajpuri, M.A.; Maguire, R.; Kavanagh, K.; Rizvi, M.M.A.; Manzoor, N.; Azam, A.; Abid, M. Effect of novel triazole-amino acid hybrids on growth and virulence of Candida species: In vitro and in vivo studies. Org. Biomol. Chem. 2016, 14, 10599-10619. [CrossRef] [PubMed]

27. Sangalli-Leite, F.; Scorzoni, L.; Alves de Paula e Silva, A.C.; de Fátima da Silva, J.; de Oliveira, H.C.; de Lacorte Singulani, J.; Gullo, F.P.; Moraes da Silva, R.; Regasini, L.O.; Siqueira da Silva, D.H.; et al. Synergistic effect of pedalitin and amphotericin B against Cryptococcus neoformans by in vitro and in vivo evaluation. Int. J. Antimicrob. Agents 2016, 48, 504-511. [CrossRef]

28. National Center for Biotechnology Information. PubChem Compound Summary for CID 31161, Pedalitin. Available online: https: / pubchem.ncbi.nlm.nih.gov / compound/Pedalitin (accessed on 5 November 2021).

29. Pratt, I.S. Global harmonisation of classification and labelling of hazardous chemicals. Toxicol. Lett. 2002, 128, 5-15. [CrossRef]

30. Allegra, E.; Titball, R.W.; Carter, J.; Champion, O.L. Galleria mellonella larvae allow the discrimination of toxic and non-toxic chemicals. Chemosphere 2018, 198, 469-472. [CrossRef] [PubMed]

31. Ignasiak, K.; Maxwell, A. Galleria mellonella (greater wax moth) larvae as a model for antibiotic susceptibility testing and acute toxicity trials. BMC Res. Notes 2017, 10,1-8. [CrossRef]

32. Maguire, R.; Duggan, O.; Kavanagh, K. Evaluation of Galleria mellonella larvae as an in vivo model for assessing the relative toxicity of food preservative agents. Cell Biol. Toxicol. 2016, 32, 209-216. [CrossRef]

33. Wu, X.; Tong, Z.-H.; Li, L.-L.; Yu, H.-Q. Toxic effects of imidazolium-based ionic liquids on Caenorhabditis elegans: The role of reactive oxygen species. Chemosphere 2013, 93, 2399-2404. [CrossRef]

34. Boškin, A.; Tran, C.D.; Franko, M. Oxidation of organophosphorus pesticides with chloroperoxidase enzyme in the presence of an ionic liquid as co-solvent. Environ. Chem. Lett. 2009, 7, 267-270. [CrossRef]

35. Luo, Y.-R.; San-Hu, W.; Li, X.-Y.; Yun, M.-X.; Wang, J.-J.; Sun, Z.-J. Toxicity of ionic liquids on the growth, reproductive ability, and ATPase activity of earthworm. Ecotoxicol. Environ. Saf. 2010, 73, 1046-1050. [CrossRef]

36. Bakshi, K.; Mitra, S.; Sharma, V.K.; Jayadev, M.S.K.; Sakai, V.G.; Mukhopadhyay, R.; Gupta, A.; Ghosh, S.K. Imidazolium-based ionic liquids cause mammalian cell death due to modulated structures and dynamics of cellular membrane. Biochim. Biophys. Acta-Biomembr. 2020, 1862, 183103. [CrossRef] [PubMed] 
37. Megaw, J.; Thompson, T.P.; Lafferty, R.A.; Gilmore, B.F. Galleria mellonella as a novel in vivo model for assessment of the toxicity of 1-alkyl-3-methylimidazolium chloride ionic liquids. Chemosphere 2015, 139, 197-201. [CrossRef] [PubMed]

38. Suay-García, B.; Alemán-López, P.A.; Bueso-Bordils, J.I.; Falcó, A.; Antón-Fos, G.; Pérez-Gracia, M.T. New solvent options for in vivo assays in the Galleria mellonella larvae model. Virulence 2019, 10, 776-782. [CrossRef]

39. Bulcão, R.P.; Freitas, F.A.; Venturini, C.G.; Dallegrave, E.; Durgante, J.; Göethel, G.; Cerski, C.T.S.; Zielinsky, P.; Pohlmann, A.R.; Guterres, S.S.; et al. Acute and subchronic toxicity evaluation of poly(E-caprolactone) lipid-core nanocapsules in rats. Toxicol. Sci. 2013, 132, 162-176. [CrossRef]

40. Cé, R.; Silva, R.C.; Trentin, D.S.; De Marchi, J.G.B.; Paese, K.; Guterres, S.S.; Macedo, A.J.; Pohlmann, A.R. Galleria mellonella larvae as an in vivo model to evaluate the toxicity of polymeric nanocapsules. J. Nanosci. Nanotechnol. 2019, 20, 1486-1494. [CrossRef] [PubMed]

41. Sheehan, G.; Dixon, A.; Kavanagh, K. Utilization of Galleria mellonella larvae to characterize the development of Staphylococcus aureus infection. Microbiology 2019, 165, 863-875. [CrossRef]

42. Capparelli, R.; Parlato, M.; Borriello, G.; Salvatore, P.; Iannelli, D. Experimental phage therapy against Staphylococcus aureus in mice. Antimicrob. Agents Chemother. 2007, 51, 2765-2773. [CrossRef]

43. Molne, L.; Verdrengh, M.; Tarkowski, A. Role of neutrophil leukocytes in cutaneous infection caused by Staphylococcus aureus. Infect. Immun. 2000, 68, 6162-6167. [CrossRef] [PubMed]

44. Kobayashi, S.D.; Malachowa, N.; Deleo, F.R. Pathogenesis of Staphylococcus aureus abscesses. Am. J. Pathol. 2015, 185, 1518-1527. [CrossRef]

45. Cheng, A.G.; Kim, H.K.; Burts, M.L.; Krausz, T.; Schneewind, O.; Missiakas, D.M. Genetic requirements for Staphylococcus aureus abscess formation and persistence in host tissues. FASEB J. 2009, 23, 3393-3404. [CrossRef] [PubMed]

46. Thomer, L.; Schneewind, O.; Missiakas, D. Pathogenesis of Staphylococcus aureus bloodstream infections. Annu. Rev. Pathol. Mech. Dis. 2016, 11, 343-364. [CrossRef]

47. Mukherjee, K.; Altincicek, B.; Hain, T.; Domann, E.; Vilcinskas, A.; Chakraborty, T. Galleria mellonella as a model system for studying Listeria pathogenesis. Appl. Environ. Microbiol. 2010, 76, 310-317. [CrossRef]

48. Drevets, D.A. Listeria monocytogenes virulence factors that stimulate endothelial cells. Infect. Immun. 1998, 66, 232-238. [CrossRef]

49. Mukherjee, K.; Hain, T.; Fischer, R.; Chakraborty, T.; Vilcinskas, A. Brain infection and activation of neuronal repair mechanisms by the human pathogen Listeria monocytogenes in the lepidopteran model host Galleria mellonella. Virulence 2013, 4, 324-332. [CrossRef] [PubMed]

50. Dutta, N.K.; Mazumdar, K.; Seok, S.H.; Park, J.H. The anti-inflammatory drug Diclofenac retains anti-listerial activity in vivo. Lett. Appl. Microbiol. 2008, 47, 106-111. [CrossRef]

51. Weichhart, T.; Costantino, G.; Poglitsch, M.; Rosner, M.; Zeyda, M.; Stuhlmeier, K.M.; Kolbe, T.; Stulnig, T.M.; Hörl, W.H.; Hengstschläger, M.; et al. The TSC-mTOR signaling pathway regulates the innate inflammatory response. Immunity 2008, 29, 565-577. [CrossRef]

52. Insua, J.L.; Llobet, E.; Moranta, D.; Pérez-Gutiérrez, C.; Tomás, A.; Garmendia, J.; Bengoechea, J.A. Modeling Klebsiella pneumoniae pathogenesis by infection of the wax moth Galleria mellonella. Infect. Immun. 2013, 81, 3552-3565. [CrossRef]

53. Cortés, G.; Borrell, N.; De Astorza, B.; Gómez, C.; Sauleda, J.; Albertí, S. Molecular analysis of the contribution of the capsular polysaccharide and the lipopolysaccharide $\mathrm{O}$ side chain to the virulence of Klebsiella pneumoniae in a murine model of pneumonia. Infect. Immun. 2002, 70, 2583-2590. [CrossRef] [PubMed]

54. Sheehan, G.; Clarke, G.; Kavanagh, K. Characterisation of the cellular and proteomic response of Galleria mellonella larvae to the development of invasive aspergillosis. BMC Microbiol. 2018, 18, 1-11. [CrossRef] [PubMed]

55. Dennis, C.G.; Greco, W.R.; Brun, Y.; Youn, R.; Slocum, H.K.; Bernacki, R.J.; Lewis, R.; Wiederhold, N.; Holland, S.M.; Petraitiene, R.; et al. Effect of amphotericin $\mathrm{B}$ and micafungin combination on survival, histopathology, and fungal burden in experimental aspergillosis in the p47 phox-/- mouse model of chronic granulomatous disease. Antimicrob. Agents Chemother. 2006, 50, 422-427. [CrossRef] [PubMed]

56. Zhang, Y.; Wu, J.; Xin, Z.; Wu, X. Aspergillus fumigatus triggers innate immune response via NOD1 signaling in human corneal epithelial cells. Exp. Eye Res. 2014, 127, 170-178. [CrossRef]

57. Alekseeva, L.; Huet, D.; Féménia, F.; Mouyna, I.; Abdelouahab, M.; Cagna, A.; Guerrier, D.; Tichanné-Seltzer, V.; Baeza-Squiban, A.; Chermette, R.; et al. Inducible expression of beta defensins by human respiratory epithelial cells exposed to Aspergillus fumigatus organisms. BMC Microbiol. 2009, 9, 33. [CrossRef]

58. Clow, L.A.; Raftos, D.A.; Gross, P.S.; Smith, L.C. The sea urchin complement homologue, SpC3, functions as an opsonin. J. Exp. Biol. 2004, 207, 2147-2155. [CrossRef] [PubMed]

59. Söderhäll, K.; Cerenius, L. Role of the prophenoloxidase-activating system in invertebrate immunity. Curr. Opin. Immunol. 1998, 10, 23-28. [CrossRef]

60. Gillespie, J.P.; Kanost, M.R.; Trenczek, T. Biological Mediators of Insect Immunity. Annu. Rev. Entomol. 1997, 42, 611-643. [CrossRef] [PubMed]

61. Gillespie, J.P.; Bailey, A.M.; Cobb, B.; Vilcinskas, A. Fungi as elicitors of insect immune responses. Arch. Insect Biochem. Physiol. 2000, 44, 49-68. [CrossRef]

62. Vasco, P.; Herriko, E.; Rementeria, A.; López-molina, N.; Ludwig, A. Genes and molecules involved in Aspergillus fumigatus virulence. Rev. Iberoam Micol. 2005, 22, 1-23.

63. Namvar, S.; Warn, P.; Farnell, E.; Bromley, M.; Fraczek, M.; Bowyer, P.; Herrick, S. Aspergillus fumigatus proteases, Asp f 5 and Asp f 13, are essential for airway inflammation and remodelling in a murine inhalation model. Clin. Exp. Allergy 2015, 45, 982-993. [CrossRef]

64. Ahmed, A.O.A.; Van Leeuwen, W.; Fahal, A.; Van De Sande, W.; Verbrugh, H.; Van Belkum, A. Mycetoma caused by Madurella mycetomatis: A neglected infectious burden. Lancet Infect. Dis. 2004, 4, 566-574. [CrossRef] 
65. Ibrahim, A.I.; El Hassan, A.M.; Fahal, A.; van de Sande, W.W. A histopathological exploration of the Madurella mycetomatis grain. PLoS ONE 2013, 8, e57774. [CrossRef]

66. Sheehan, G.; Konings, M.; Lim, W.; Fahal, A.; Kavanagh, K.; van de Sande, W.W.J. Proteomic analysis of the processes leading to Madurella mycetomatis grain formation in Galleria mellonella larvae. PLoS Negl. Trop. Dis. 2020, 14, e0008190. [CrossRef]

67. Seitz, V.; Clermont, A.; Wedde, M.; Hummel, M.; Vilcinskas, A.; Schlatterer, K.; Podsiadlowski, L. Identification of immunorelevant genes from greater wax moth (Galleria mellonella) by a subtractive hybridization approach. Dev. Comp. Immunol. 2003, 27, 207-215. [CrossRef]

68. De Klerk, N.; De Vogel, C.; Fahal, A.; Van Belkum, A.; Van De Sande, W.W.J. Fructose-bisphosphate aldolase and pyruvate kinase, two novel immunogens in Madurella mycetomatis. Med. Mycol. 2012, 50, 143-151. [CrossRef]

69. Cutuli, M.A.; Petronio Petronio, G.; Vergalito, F.; Magnifico, I.; Pietrangelo, L.; Venditti, N.; Di Marco, R. Galleria mellonella as a consolidated in vivo model hosts: New developments in antibacterial strategies and novel drug testing. Virulence 2019, 10, 527-541. [CrossRef]

70. Sheehan, G.; Farrell, G.; Kavanagh, K. Immune priming: The secret weapon of the insect world. Virulence 2020, 11, 238-246. [CrossRef]

71. Barnoy, S.; Gancz, H.; Zhu, Y.; Honnold, C.L.; Zurawski, D.V.; Venkatesan, M.M. The Galleria mellonella larvae as an in vivo model for evaluation of Shigella virulence. Gut Microbes 2017, 8, 335-350. [CrossRef] 